\section{Rise in retractions is a signal of integrity}

A stigma should not be attached to the retraction of a scientific paper, as you explain (Nature 507, 389-391; 2014). It should also be emphasized that the rise in retractions over the past few years does not signify a surge in misconduct: on the contrary, it reflects a growing scientific integrity.

Too many academics and journalists conflate retractions with the falsification of results. However, retractions account for less than $0.02 \%$ of publications annually - a fraction of the $2 \%$ of scientists who admit in anonymous surveys to having manipulated data at least once (see D. Fanelli PLoS ONE 4, e5738; 2009).

The majority of formal retractions have been issued in recent years, with none before the 1970s. A growing number of journals are now prepared to publish retractions, and the apparent increase in retraction rate disappears after correcting for this factor (see D. Fanelli PLoS Med. 10, e1001563; 2013).

Retractions are therefore more logically and usefully interpreted as evidence for the commitment of editors and scientists to remove invalid results from the literature. Daniele Fanelli University of Montreal, Canada. email@danielefanelli.com

\section{Practical costs of data sharing}

Aside from the ethics and etiquette of fully open datasharing (Nature 507, 140; 2014), there are practical issues that journals still need to address.

One is the cost of sharing data. Both the Public Library of Science and the UK Royal Society recommend the storage repository Dryad, which currently charges US $\$ 15$ for the first gigabyte of data over its 10-gigabyte limit, and $\$ 10$ per gigabyte thereafter.
However, studies in areas such as neuroscience can generate terabytes of raw data (1 terabyte is 1,000 gigabytes) - a quantity that few labs could afford to upload.

And, given that searching Dryad for 'neuroscience' yields just three papers but 2,286 for 'ecology', a 'one-size-fits-all' data-sharing policy may not work across all disciplines.

Another concern is the availability of new computer code. Researchers often write their own data-analysis code for each new study, but do not always document it fully. Making code usable by others may therefore require considerable extra work - particularly given the diversity of computing platforms and software versions (see also N. Barnes Nature 467, 753; 2010).

These challenges also vary by discipline: analysis may comprise a few lines of code in some fields but thousands in others, as dictated by the requirements of individual papers.

Geoffrey J. Goodhill University of Queensland, St Lucia, Australia. g.goodhill@uq.edu.au

\section{Scottish separation could harm science}

On 18 September, there will be a referendum in Scotland to decide whether it should become an independent country. As scientists and members of the campaign group Academics Better Together, we feel that Colin Macilwain gives an incomplete picture of Scottish science (Nature 493, 579; 2013): we strongly believe that its brightest future is as part of the United Kingdom.

Scientists in Scotland benefit from being part of the large, efficient UK research community, in which competition and collaboration drive high-ranking research. As a small independent nation, Scotland would be forced to drop out of many research areas because it could no longer afford large-scale infrastructure. Collaborative research is likely to be more difficult across a national border. Also, Scotland would lose its disproportionately high block grant from the UK government, allocated in part to fund research and education in its universities.

The Scottish National Party's White Paper recognizes all this. The party wants Scotland to remain in the UK researchcouncil system, but there are political indications that this may not be an option. The Wellcome Trust and the Association of Medical Research Charities have declared that it would be hard to fund research in another country. Scottish medical research would also be affected by restricted access to large UK clinical trials.

In our view, separating from the United Kingdom would leave scientists in Scotland with much to lose, for imperceptible gain. Hugh Pennington Aberdeen, UK. Susan A. Shaw Dunblane, UK. Andrew Miller Edinburgh, UK. miller_andrew1@sky.com

\section{Former Iron Curtain safeguards wildlife}

Aaron Ellison calls for conservation efforts across countries to offset the adverse effects of political borders on wildlife (Nature 508, 9; 2014). The European Green Belt (www.europeangreenbelt.org), which is converting former cold-war territory in central and eastern Europe into a network of protected conservation areas, is one such initiative that should serve as a model for other regions with a history of strife.

The European Green Belt was instigated in 2003 and stretches 12,500 kilometres along the former Iron Curtain, the political barrier that existed from 1945 until 1989. The belt consists of protected core areas, sustainableuse areas, ecological corridors and buffer zones, which provide linked habitats and migration routes for such animals as wolves, bears and lynxes, as well as for amphibians and birds.

Not least, it offers a symbol of reconciliation, enjoying the patronage of Mikhail Gorbachev, former Soviet Union president. Bernhard Jank, Johannes Rath University of Vienna, Austria. bernhard.jank@outlook.com

\section{Two brains and a forgotten theory}

Two Nature papers published 100 years apart on the role of tension in brain cortex folding are connected by a historical footnote.

I discovered this as a result of a coincidence: the brain of the poet Walt Whitman and that of anatomist Andrew Parker ended up in a lab waste bin after dying within a week of one another in 1892. Both had been collected by the secretive American Anthropometric Society, which sought to uncover neuroanatomical features in the brains of eminent people. Unfortunately, Whitman's brain shattered after being dropped on the floor; Parker's crumbled after soaking in fixative for too long.

Beyond this shared fate of neural machinery, there is little information about Parker himself. My investigations revealed that he had proposed a mathematical theory of cortical folding based on the laws of liquid films and surface tension (see W. B. Benham Nature 55, 619-620; 1897) - ironic, considering that the laws of liquid physics and chemical reactions crumbled his brain. I also found that his conclusions nicely complement a theory put forward a century later (D. C. Van Essen Nature 385, 313-318; 1997).

Kevin S. Weiner Stanford University; and the Institute for Applied Neuroscience, California, USA.

kweiner@stanford.edu

\section{CORRECTION}

The data for the graphic in P. Ginsparg's Correspondence (Nature 508, 44; 2014) were incorrectly credited to C. Labbé, who provided just a subset of the raw data used by the author. 